\title{
Spur Characteristics, Fruit Growth, and Carbon Partitioning in Two Late-maturing Japanese Pear (Pyrus pyrifolia Nakai) Cultivars with Contrasting Fruit Size
}

\author{
Caixi Zhang \\ United Graduate School of Agricultural Sciences, Tottori University, Tottori 680-8533, Japan
}

Kenji Tanabe', Fumio Tamura, and Akihiro Itai

Laboratory of Horticultural Science, Faculty of Agriculture, Tottori University, Tottori 680-8533, Japan

\author{
Shiping Wang \\ Department of Plant Science, College of Agriculture and Biology, Shanghai Jiaotong University, \\ Shanghai 201101, P.R. China
}

AdDitional INDEX wORDs. ${ }^{13} \mathrm{CO}_{2}$, photosynthesis, sink strength, fruit development

\begin{abstract}
Aвstract. The aim of this study was to investigate the roles of spur characteristics and carbon partitioning in regulating cultivar differences in fruit size of two late-maturing japanese pear cultivars, 'Atago' and 'Shinkou'. The study of spur characteristics showed that the two cultivars displayed different patterns in leaf development, flower characteristics, fruit growth, and shoot type. In contrast to 'Atago' with dramatically larger fruit, 'Shinkou' is a heavily spurred cultivar with a higher total leaf area and leaf number per spur early in fruit growth, less vegetative shoots, and smaller fruit but larger core. No significant differences were obtained in specific leaf weight, leaf thickness, chlorophyll content, and net photosynthesis of mature leaves, and seed number per fruit between the two cultivars. The results of trace experiment with ${ }^{13} \mathrm{C}$ revealed that on a spur basis, there were no significant differences in the amount of ${ }^{13} \mathrm{C}$ assimilate produced by spur leaves on each labeling date except at 190 days after anthesis, however, there were highly significant differences in the amount of ${ }^{13} \mathrm{C}$ allocated to fruit between cultivars. Moreover, a higher amount of ${ }^{13} \mathrm{C}$ assimilates was allocated to 'Atago' flesh (or fruit) than that in 'Shinkou'. Analysis of relative sink strength (RSS) indicates that the sink strength of fruit was dominant over those of other organs in the spur measured in both cultivars except at the early stage of fruit growth. 'Atago' exhibited a greater RSS of fruit and lower losses of ${ }^{13} \mathrm{C}$ for respiration and export than 'Shinkou'. These results suggest that the movement of photosynthates into the fruit was determined by sink strength of the fruit rather than the source strength in the two cultivars.
\end{abstract}

Fruit size is a very important characteristic for pear production and trade in many countries. Consumers, in particular in Japan and China, prefer larger pears, and therefore the production of larger pears is more profitable. In general, fruit size of pear is influenced by many factors, such as genetic background, culture techniques, and environmental effects (Garrizet al., 1998; Hayashi and Tanabe, 1991; Jackson, 2003). For the purpose of producing larger fruit, many techniques were developed for the manipulation of balance between the tree and environment in practical culture (Hayashi and Tanabe, 1991; Jackson, 2003).

It is well known that nondomesticated and cultivated Pyrus display a wide range of sizes and shapes of fruit (Laney and Quamme, 1975). In japanese pears, both 'Atago' and 'Shinkou' are late-season cultivars with russet-brown fruit and are the progenies of crosses made between 'Nijisseiki' and unknown cultivars in Japan, but they display different growth habit and fruit quality. 'Atago' is harvested in early November and its trees are spur type, moderately vigorous, and productive. It is notable for having the largest fruit among japanese pears, weighing as much as $\approx 1500-2000 \mathrm{~g}$. Because of the Japanese preference for large pears, 'Atago' is widely grown as a gift-pear in western

Received for publication 31 Mar. 2004. Accepted for publication 8 Oct. 2004. ${ }^{1}$ Corresponding author; e-mail tanabe@muses.tottori-u.ac.jp
Japan, especially Okayama Prefecture. 'Shinkou' is harvested 2-3 weeks earlier than 'Atago'. Its trees are moderately vigorous with a heavily spurred habit in its early years after planting and subsequently characterized by weak growth. Although the fruit of 'Shinkou' is not as large as that of 'Atago' (medium- to large-sized fruit of 400-500 g), its good eating and storage ability have attracted many consumers (Machida, 2000). Except for three dominant cultivars ('Kousui', 'Housui', and 'Nijisseiki'), 'Shinkou' held second place and 'Atago' held third place in the 2001 total production area of japanese pear in Japan after 'Niitaka' [National Institute of Fruit Tree Science (NIFTS), 2002]

Although much attention has been concentrated on fruit size in many crops during the past several decades, the cultivar differences in fruit size are neither well clarified nor fully understood. It has been shown that final fruit size is closely linked to cell number and cell size in japanese pear as well as most fruit trees (Hayashi and Tanabe, 1991). Any factors that can influence the above aspects would result in changes of final fruit size. In addition, because spur is an important fruiting structure in japanese pear, its characteristics are also critical for fruit development. It has been demonstrated that morphological variations of spur are correlated with light environment and variations in fruit size and quality in apple (Malus $\times$ domestica Borkh.) cultivars (Ferree et al., 2001; Rom and Ferree, 1984; Tustin et al., 1992). Also, the 
differences in spur characteristics were proposed to account for the variations of final fruit size among japanese pears with different harvest seasons (Zhang, 2003).

The partitioning of photoassimilates from spur leaves is another key factor for fruit development. In previous reports, leaf emergence rate, leaf number, and spur age were correlated with carbohydrate partitioning, which resulted in the variations of fruit size and production in 'Nijisseiki' pear (Hayashi and Tanabe, 1991; Teng et al., 2002). In japanese pear, the distribution of photoassimilates from spur leaves during the period of rapid fruit growth and the importance of reserves for fruit growth were partially elucidated (Teng et al., 1999, 2001; Yamamoto, 2001), but little information about the differences of carbon partitioning between cultivars during fruit development was presented. 'Atago' and 'Shinkou' have similar durations of cell division and period of fruit growth but large differences in fruit size. It has been suggested that an unidentified virus may be responsible for small fruit of 'Shinkou' because of its mosaic-like leaves, however, little progress has been made. Moreover, even if reducing croploads, the fruit size of 'Shinkou' could not be retrievable significantly (Machida, 2000). For better understanding how the partitioning of photosynthates attributes for final fruit size and developing suitable cultural practices to improve yield and fruit quality, the following experiments were initiated to evaluate the differences in spur characteristics, fruit growth, and the partitioning of photosynthates from spur leaves in the two late-maturing cultivars of japanese pear during fruit development by ${ }^{13} \mathrm{CO}_{2}$ tracer.

\section{Materials and Methods}

Plant materials. Experiments were carried out in the experimental orchard of Tottori Univ., Tottori, Japan. Two 12-year-old late-maturing japanese pear cultivars, 'Shinkou' and 'Atago', grafted onto Pyrus betulaefolia Bunge rootstocks were selected for experiments. Trees were spaced $4 \times 5 \mathrm{~m}$ apart and were trained to a flat-canopied, pergola system. All classes of scaffolds and lateral branches were tied to a horizontal trellis (Teng et al., 1998). Cultural management practices, such as fertilization, pruning, pest control, and thinning, were conducted the same as in a commercial orchard. Flowers were hand-pollinated with pollens of 'Chojuro' pear during full bloom. Each spur was hand-thinned to one fruit at 4 weeks after anthesis (WAA) and the number of fruit per tree was adjusted to $\approx 130-180$ in both cultivars under the normal cropping manipulations in Japan. To determine the level of cropload in this type of management system, the trunk diameter was measured by digital caliper and the level of cropload was quantified by calculating the number of pears per square centimeter of trunk cross-sectional area (TCA). The range of croploads for the two cultivars was $0.8-1.5 \mathrm{fruit} / \mathrm{cm}^{2}$ of TCA.

Characteristics of LeAF, Flower, Fruit, AND SHOOT TYPE. After anthesis, 2-year-old fruiting spurs without bourse shoot were sampled for collecting related data. Number of leaves per spur was counted and mature leaves were selected for measurement of leaf thickness and chlorophyll content (Raskin, 1983). Total leaf area per spur was recorded using a LI-3000A portable leaf area meter (LI-COR, Lincoln, Nebr.). Leaves were dried at $65^{\circ} \mathrm{C}$ for dry weight determination and specific leaf weight (SLW) was calculated by the formula SLW = leaf dry weight/leaf area.

In addition to flower number per spur, pedicel dry weight, pedicel length and diameter at anthesis and harvest were also investigated. Fresh weight, dry weight, diameter, and length of fruit were recorded at weekly intervals. At harvest, seed number (viable and shriveled seeds), fresh weight of flesh (cortex of receptacle), core (pith of receptacle + pericarp + seeds), and seed were determined. The volume of flesh and core was measured by water displacement.

For shoot growth, there are three shoot types with the exception of vegetative shoot (VS, nonfruiting shoot) and water shoot (WS) in japanese pears: fruiting spurs without bourse shoot (F), fruiting spurs with bourse shoot (FB), and fruiting spurs with only one bourse shoot (FOB). Four plants with uniform vigor in each cultivar were used for counting the number of each type of fruiting spurs, vegetative shoot, and water shoot on the lateral branch at harvest. The results were presented as percentage.

${ }^{13}$ C LABEling AND MEASUREMENT OF NET PHOtOSYNTHESIS. The labeling experiment with ${ }^{13} \mathrm{CO}_{2}$ was carried out at five stages during fruit growth: 30, 60, 110, 150, and 190 days after anthesis (DAA). Two-year-old fruiting spurs without bourse shoot on lateral branch with uniform vigor were selected for the ${ }^{13} \mathrm{C}$ labeling study. One tree represented a replication and four trees were selected on each cultivar. Two fruiting spurs per tree were selected and one of them was girdled on the bark of base with 2-mm-wide incisions immediately to prevent export of photoassimilates from the spur unit before ${ }^{13} \mathrm{CO}_{2}$ labeling for the determination of total amount of ${ }^{13} \mathrm{C}$ recovered in spur Because the fruit contained chlorophyll in the green tissue, especially during the initial stage of fruit development, they were enclosed with aluminum film to prevent them from fixing carbon dioxide. Individual spur was exposed to ${ }^{13} \mathrm{CO}_{2}$ enclosed in a polyethylene bag. The ${ }^{13} \mathrm{CO}_{2}$ was generated through injecting 2-3 $\mathrm{mL} \mathrm{70 \%} \mathrm{lactic} \mathrm{acid} \mathrm{into} \mathrm{a} \mathrm{25-}$ $\mathrm{mL}$ glass vial that contained $0.8 \mathrm{~g} \mathrm{Ba}^{13} \mathrm{CO}_{3}$ with an abundance of $99 \%{ }^{13} \mathrm{C}$ (Cambridge Isoptope Laboratories, Andover, Mass.) and fixed on the frame in the polyethylene bag. To ensure uniform labeling among the spurs, $1.5 \mathrm{~h}$ after the start of ${ }^{13} \mathrm{C}$ labeling, nonlabeled $\mathrm{CO}_{2}$ was produced by injecting lactic acid into another vial containing $1 \mathrm{~g}$ of $\mathrm{BaCO}_{3}$ in the polyethylene bag. The whole labeling process lasted for $2 \mathrm{~h}$ between 0800 and $1000 \mathrm{HR}$ under ambient field conditions with clear skies at 30, 60, and 190 DAA. At 110 and $150 \mathrm{DAA}$, the whole labeling process was undertaken between 0730 and $0930 \mathrm{HR}$ because of high temperature in the morning. During the period of ${ }^{13} \mathrm{C}$ labeling, net photosynthesis (Pn) measurement of individual mature leaves from fruiting spurs were taken using a Shimadzu portable photosynthesis system (Analytical Development Co., Hoddesdon, Hertfordshire, U.K.). The third or fourth leaf from the base of spur was used for Pn measurement in a spur. Each leaf was a single replication, and there were four replications per cultivar.

The four girdled spurs were harvested immediately after labeling. The remaining spurs were harvested $7 \mathrm{~d}$ after labeling (DAL). The harvested spurs were immediately separated into leaves, current shoots (stem parts), old wood, and fruit, then stored on ice and transported to laboratory. Fruit were further divided into flesh, core, and pedicel. The divided parts of fruit were freezedried and their dry weights were determined. After the number of leaves per spur was counted, individual leaf area was measured and the total leaf area per spur was calculated. Leaves, slices of current shoots, and old wood cut with amputate scissors were oven-dried at $65^{\circ} \mathrm{C}$ for $10 \mathrm{~d}$ to a constant dry weight. Samples from each section were ground finely in a coffee mill and stored in a glass vial for further analyses.

Measurement OF ${ }^{13} \mathrm{C} .{ }^{13} \mathrm{C}$ abundance and carbon contents were determined using an infrared ${ }^{13} \mathrm{CO}_{2}$ analyzer (model EX-130S; Japan Spectroscopic Co., Tokyo) after combustion of a sample at $900{ }^{\circ} \mathrm{C}$ in an $\mathrm{O}_{2}$ stream according to the method developed 
by Okano et al. (1983) and Kouchi and Yoneyama (1984). The abundance of ${ }^{13} \mathrm{C}$ was expressed as atom percent. The amounts of labeled ${ }^{13} \mathrm{C}$ recovered in each organ were given as total carbon in each organ $\times{ }^{13} \mathrm{C}$ atom percent and expressed as $\mathrm{mg}$. The total amount of ${ }^{13} \mathrm{C}$ recovered from the girdled spurs harvested immediately after ${ }^{13} \mathrm{CO}_{2}$ labeling was used as the basis for calculating the proportion and amount of ${ }^{13} \mathrm{C}$ losses for respiration and export from the spur. The losses of ${ }^{13} \mathrm{C}$ for respiration and export were estimated by calculating the difference between total ${ }^{13} \mathrm{C}$ recovered from girdled spurs harvested immediately after ${ }^{13} \mathrm{CO}_{2}$ labeling and ${ }^{13} \mathrm{C}$ amount in spurs harvested $7 \mathrm{~d}$ after labeling.

Calculation OF SINK STRENGTH AND RElative SINK STRENGTH. In this study, the ${ }^{13} \mathrm{C}$ abundance of each organ was expressed as atom percentage. Comparison of the ability of dry matter partitioning was made on sink strength and relative sink strength (RSS) because of variations in the amount of recovered ${ }^{13} \mathrm{C}$ among treatments and weight of plant organs. Sink strength has been considered as a product of sink size and sink activity (Ho, 1988). The ${ }^{13} \mathrm{C}$ abundance of each organ was regarded as sink specific activity, and dry weight of sink was calculated as sink size. The RSS was calculated by dividing the sink strength of an individual organ by the sum of sink strengths of the whole spur, and the result expressed as a percentage of the total (Shishido et al., 1999; Treder and Kubik, 2000).

Statistical analysis. Data were analyzed by Student's $t$ test using Sigmaplot (Jandel Scientific, San Rafael, Calif.) software. A probability of $P>0.05$ was considered nonsignificant. a relatively shorter period of fruit enlargement, longer maturation stage, and moderate slope of growth curve during the linear stage than 'Atago' (Fig. 1 and Table 1). It was very clear that 'Atago' had a significantly smaller core in fresh weight and volume than 'Shinkou'. No differences were measured in seed number and fresh weight between cultivars.

The investigation of shoot types on lateral branches showed that 'Shinkou' is a heavily spurred cultivar with more than $90 \%$ fruiting spur and has an extremely low proportion of vegetative shoot (Table 2). Although 'Atago' is also a spur-type cultivar, a lower proportion of fruiting spur and a higher one of vegetative shoot were observed in this study compared to 'Shinkou'. No differences were found in the proportion of water shoot between the two cultivars.

${ }^{13}$ C TRanslocation and Partitioning. On the basis of spur, there were no significant differences in the amount of ${ }^{13} \mathrm{C}$ assimilates produced by spur leaves at 30, 60, 110, 150 DAA except at 190 DAA between 'Atago' and 'Shinkou' (Table 3). Even if expressed on the basis of leaf area, a similar result was obtained (data not shown). Similarly, no significant differences in Pn of mature spur leaves were measured between the two cultivars on each labeling date except at 190 DAA.

The amount of ${ }^{13} \mathrm{C}$ allocated to fruit in $2 \mathrm{~h}$ after ${ }^{13} \mathrm{C}$ labeling could be used for an indirect indicator of assimilates import rate. As shown in Table 4, 'Atago' exhibited significantly higher rates of assimilates import than 'Shinkou' at 60, 150, and 190 DAA.

After $7 \mathrm{~d}$ of ${ }^{13} \mathrm{CO}_{2}$ labeling, the amount ${ }^{13} \mathrm{C}$ allocated to individual organs in the spur varied with the stage of fruit development

\section{Results}

Characteristics OF Leaf, Flower, Fruit, AND SHOOT TYPE. Two late-maturing cultivars measured in this study displayed different growth patterns in total spur leaf area and leaf number per spur (Fig. 1). In 'Shinkou', most leaves emerged before full bloom and unfolded leaf number per spur increased rapidly from 7.3 at 1 WAA to a plateau of $\approx 13.3$ at 4 WAA, which could be maintained toward fruit harvest. In contrast, more secondary leaves developed on the spurs after flowering in 'Atago', and it took $\approx 2.5$ months to complete and approach a similar leaf number after full bloom. Similarly, total leaf area per spur of 'Shinkou' increased sharply and was greater than that of 'Atago' until the occurrence of nonsignificant difference at 8 WAA between the two cultivars. No significant differences were obtained in SLW, leaf thickness, and chlorophyll content with mature leaves (Table 1).At full bloom, there were significant differences in flower number per spur, peduncle length, and diameter between the two cultivars. 'Shinkou' exhibited a higher flower number per spur and smaller peduncles compared to 'Atago'.

Seasonal fruit development in both cultivars followed a single sigmoid growth curve based on the measurement of fresh weight (Fig. 2) as well as dry weight, fruit diameter, and length (data not shown). Around 10 WAA, 'Atago' fruit started to enter into the stage of rapid fruit growth. However, there was an $\approx 2$-week lag in fruit fresh weight before the start of rapid fruit growth in 'Shinkou'. On the other hand, 'Shinkou' displayed

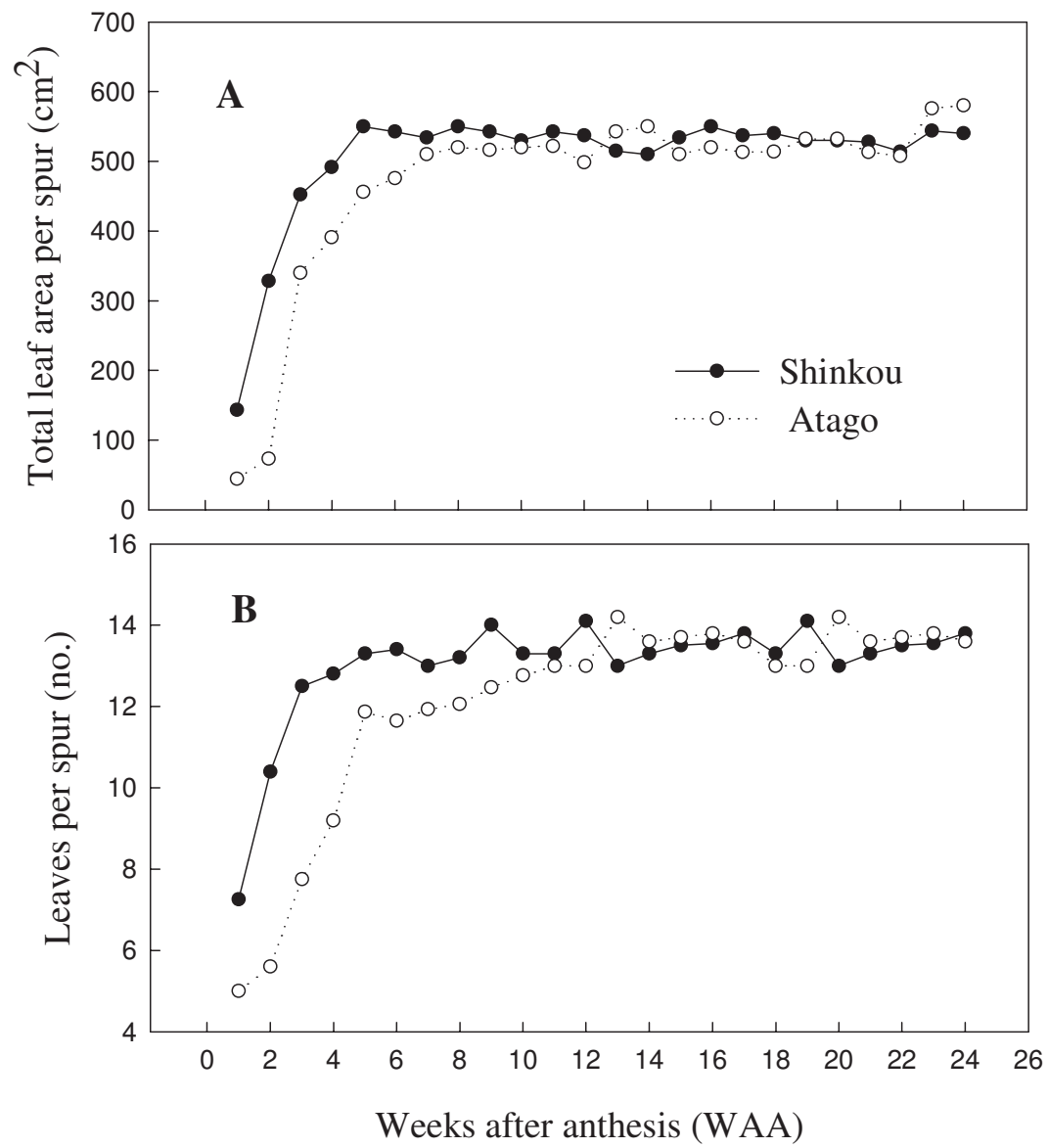

Fig. 1. Changes in total leaf area (A) and leaf number $(\mathbf{B})$ per spur after anthesis in two late-maturing japanese pear cultivars, 'Shinkou' and 'Atago' $(\mathrm{n}=7)$. 
Table 1. Characteristics of leaf, flower, and fruit in two late-maturing japanese pear cultivars, 'Shinkou' and 'Atago'. Values are means $\pm \mathrm{SE}, \mathrm{n}=30$.

\begin{tabular}{|c|c|c|c|}
\hline \multirow[b]{2}{*}{ Parameter measured } & \multicolumn{2}{|c|}{ Cultivar } & \multirow[b]{2}{*}{ Significance } \\
\hline & Shinkou & Atago & \\
\hline \multicolumn{4}{|l|}{$\overline{\text { Leaf }^{z}}$} \\
\hline Specific leaf weight $\left(\mathrm{mg} \cdot \mathrm{mm}^{-2}\right)$ & $0.11 \pm 0.01$ & $0.11 \pm 0.01$ & NS \\
\hline Leaf thickness (mm) & $0.26 \pm 0.02$ & $0.27 \pm 0.01$ & NS \\
\hline Total chlorophyll content $\left(\mu \mathrm{g} \cdot \mathrm{mm}^{-2}\right)$ & $1.43 \pm 0.05$ & $1.47 \pm 0.04$ & NS \\
\hline \multicolumn{4}{|l|}{ Flower } \\
\hline Flower number/spur & $8.98 \pm 2.3$ & $7.04 \pm 1.6$ & $* *$ \\
\hline Peduncle length (mm) & $24.69 \pm 2.58$ & $29.98 \pm 2.8$ & $* *$ \\
\hline Peduncle diameter (mm) & $1.40 \pm 0.13$ & $1.41 \pm 0.18$ & NS \\
\hline \multicolumn{4}{|l|}{ Fruit } \\
\hline Fruit FWy (g) & $545.6 \pm 23.6$ & $1207 \pm 77.5$ & $* *$ \\
\hline Core FW (g) & $56.8 \pm 8.6$ & $38.8 \pm 6.7$ & $* *$ \\
\hline Core /fruit (v/v) & $1 / 10$ & $1 / 33$ & $* *$ \\
\hline Fruit diameter $(\mathrm{mm})$ & $102.7 \pm 3.5$ & $141.7 \pm 3.9$ & $* *$ \\
\hline Fruit length (mm) & $94.3 \pm 1.8$ & $117 \pm 3.8$ & * \\
\hline Seed number/fruit & $10.30 \pm 0.72$ & $9.89 \pm 0.33^{x}$ & NS \\
\hline Seed FW/fruit (g) & $0.84 \pm 0.09$ & $0.74 \pm 0.22^{w}$ & NS \\
\hline Pedicel length (mm) & $30.5 \pm 1.5$ & $34.2 \pm 3.3$ & $*$ \\
\hline Pedicel diameter (mm) & $3.67 \pm 0.19$ & $4.15 \pm 0.32$ & $* *$ \\
\hline
\end{tabular}

zThe leaf, flower and fruit were sampled from fruiting spur at $60,0 \mathrm{~d}$ after anthesis and at harvest, respectively.

$\mathrm{y} F \mathrm{~W}=$ fresh weight, $\mathrm{v} / \mathrm{v}=$ ratio of volume.

$\mathrm{x}$, wThere were about $1 / 4$ shriveled seeds.

Ns, *,**Nonsignificant or significant at $P<0.05$ or 0.01 , respectively, by $t$ test.

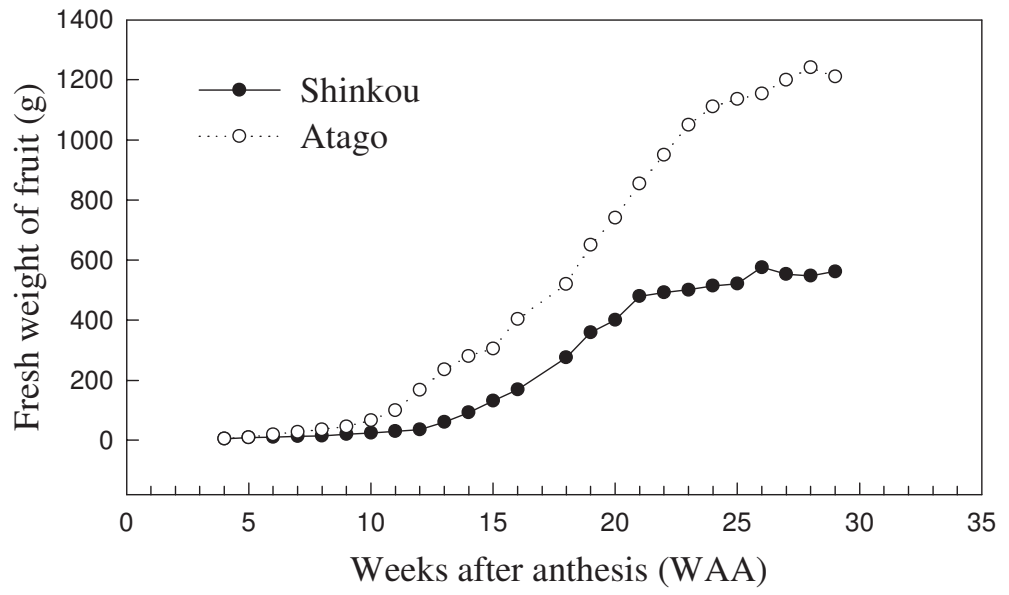

Fig. 2. Changes of fruit fresh weight during fruit development in two late-maturing japanese pear cultivars, 'Shinkou' and 'Atago' $(n=7)$.

Table 2. Percentage distribution of shoot types on lateral branches in two late-maturing japanese pear cultivars, 'Shinkou' and 'Atago' $(n=4)$.

\begin{tabular}{lccc}
\hline & \multicolumn{3}{c}{ Cultivar (\%) } \\
\cline { 2 - 4 } Shoot type & Shinkou & Atago & Significance \\
\hline $\mathrm{F}^{\mathrm{z}}$ & 80.00 & 62.03 & $* *$ \\
$\mathrm{FB}^{\mathrm{y}}$ & 13.18 & 4.22 & $* *$ \\
$\mathrm{FOB}^{\mathrm{x}}$ & 0.32 & 11.93 & $* *$ \\
$\mathrm{VS}$ & 4.75 & 15.56 & $* *$ \\
$\mathrm{WS}$ & 2.00 & 6.80 & NS
\end{tabular}

${ }^{\mathrm{z}} \mathrm{F}=$ fruiting spur without bourse shoot, $\mathrm{FB}=$ fruiting spur with bourse shoot, $\mathrm{FOB}$ = fruiting spurs with only one bourse shoot, $\mathrm{VS}=$ vegetative shoot, $\mathrm{WS}=$ water shoot.

$\mathrm{y}, \mathrm{x}$ Second growth of bourse shoot occurs in July.

Ns, **Nonsignificant or significant at $P<0.01$, respectively, by $t$ test.
(Table 5). Most of ${ }^{13} \mathrm{C}$ photoassimilates were allocated to the fruit except that there was a relative higher retention rate of ${ }^{13} \mathrm{C}$ in the leaf at $37 \mathrm{DAA}$. Both the amount and proportion of ${ }^{13} \mathrm{C}$ assimilates incorporated to fruit after ${ }^{13} \mathrm{C}$ labeling in 'Atago' were significantly higher than those in 'Shinkou' on each measuring date. There was only a small proportion of ${ }^{13} \mathrm{C}$ recovered in current shoot and a subsequent decline was observed in both cultivars, but they displayed distinct patterns of ${ }^{13} \mathrm{C}$ distribution in old wood. In 'Shinkou', the amount of ${ }^{13} \mathrm{C}$ increased from 30 DAA and peaked at 67 DAA whereafter it gradually decreased toward maturation, while it tended to be higher in the early stage of fruit development in 'Atago' and followed by a decline after 37 DAA.

A further analysis of ${ }^{13} \mathrm{C}$ distribution in fruit revealed that the amount of ${ }^{13} \mathrm{C}$ in flesh shared the largest proportion of total ${ }^{13} \mathrm{C}$ recovered in fruit in both cultivars (Table 5). Moreover, there were also highly significant differences in the amount of ${ }^{13} \mathrm{C}$ in flesh between the two cultivars at 37, 67, 157, and 197 DAA except at 117 DAA. However, no significant differences were observed in amount of ${ }^{13} \mathrm{C}$ recovered in the core between the two cultivars except that at $197 \mathrm{DAA} .{ }^{13} \mathrm{C}$ recovered in the core increased and reached a maximum amount at 117 DAA, then subsequently declined toward fruit maturation, but in 'Shinkou' there was a dramatic increase again at $197 \mathrm{DAA}$. The amount of ${ }^{13} \mathrm{C}$ recovered in pedicel on both cultivars at 37 DAA was the highest among the measuring dates and subsequently declined although there was only a small proportion of ${ }^{13} \mathrm{C}$ recovered in pedicel of the two cultivars.

${ }^{13}$ C LOSSES OF RESPIRATION AND EXPORT. In this eXperiment, the ${ }^{13} \mathrm{C}$ losses of respiration and export were 
Table 3. Net photosynthetic rate (Pn) of spur leaf, amount of ${ }^{13} \mathrm{C}$ recovered in spur in $2 \mathrm{~h}$ and $7 \mathrm{~d}$ after ${ }^{13} \mathrm{CO}_{2}$ labeling and losses for respiration and export in $7 \mathrm{~d}$ after ${ }^{13} \mathrm{CO}_{2}$ labeling in two japanese pear cultivars, 'Shinkou' and 'Atago' $(\mathrm{n}=4)$.

\begin{tabular}{|c|c|c|c|c|c|c|}
\hline \multirow[b]{2}{*}{$\mathrm{DAA}^{\mathrm{z}}$} & \multirow[b]{2}{*}{ Cultivar } & \multirow{2}{*}{$\begin{array}{c}\mathrm{Pn} \\
\left(\mu \mathrm{mol} \cdot \mathrm{m}^{-2} \cdot \mathrm{s}^{-1} \mathrm{CO}_{2}\right)\end{array}$} & \multicolumn{2}{|c|}{ Amount of ${ }^{13} \mathrm{C}$ recovered $(\mathrm{mg})$} & \multicolumn{2}{|c|}{ Losses of respiration and export } \\
\hline & & & $2 \mathrm{HAL}^{\mathrm{x}}$ & 7 DAL & Amount (mg) & Proportion $^{\mathrm{w}}(\%)$ \\
\hline \multirow[t]{3}{*}{$30^{v}$} & Shinkou & 16.49 & 25.53 & 13.18 & 12.35 & 48.36 \\
\hline & Atago & 14.84 & 22.64 & 20.07 & 2.57 & 11.35 \\
\hline & & NS & NS & $* *$ & $* *$ & $* *$ \\
\hline \multirow[t]{3}{*}{60} & Shinkou & 17.03 & 19.95 & 9.78 & 10.17 & 50.99 \\
\hline & Atago & 16.88 & 26.43 & 20.87 & 5.56 & 21.18 \\
\hline & & NS & NS & $* *$ & NS & $* *$ \\
\hline \multirow[t]{3}{*}{110} & Shinkou & 18.43 & 27.09 & 26.80 & 0.29 & 1.07 \\
\hline & Atago & 17.55 & 30.80 & 30.20 & 0.60 & 1.95 \\
\hline & & NS & NS & NS & NS & NS \\
\hline \multirow[t]{3}{*}{150} & Shinkou & 18.03 & 25.44 & 13.66 & 11.78 & 46.32 \\
\hline & Atago & 17.31 & 31.13 & 31.04 & 0.09 & 0.29 \\
\hline & & NS & NS & $* *$ & $* *$ & $* *$ \\
\hline \multirow[t]{3}{*}{190} & Shinkou & ---u & 25.03 & 23.89 & 1.14 & 4.59 \\
\hline & Atago & --- & 48.51 & 33.84 & 14.67 & 30.25 \\
\hline & & --- & $* *$ & NS & $* *$ & $* *$ \\
\hline
\end{tabular}

${ }^{2} \mathrm{DAA}=$ days after anthesis.

yThe total amount of ${ }^{13} \mathrm{C}$ recovered in whole spur include leaves, current shoot, old wood and fruit.

${ }^{x} \mathrm{HAL}=$ hours after ${ }^{13} \mathrm{C}$ labeling, $\mathrm{DAL}=$ days after ${ }^{13} \mathrm{C}$ labeling.

wThe losses of ${ }^{13} \mathrm{C}$ for respiration and export from the spur during $7 \mathrm{~d}$ after labeling was calculated as a percentage of the total ${ }^{13} \mathrm{C}$ recovered from girdled spurs harvested $2 \mathrm{~h}$ after ${ }^{13} \mathrm{CO}_{2}$ labeling.

${ }^{\mathrm{v} 13} \mathrm{CO}_{2}$ labeling date.

uData was lost.

Ns, *,**Nonsignificant or significant at $P<0.05$ or 0.01 , respectively, by $t$ test.

Table 4. Amount of ${ }^{13} \mathrm{C}$ allocated to fruit of fruiting spur in $2 \mathrm{~h}$ after ${ }^{13} \mathrm{CO}_{2}$ labeling in two late-maturing japanese pear cultivars, 'Shinkou' and 'Atago' $(\mathrm{n}=4)$.

\begin{tabular}{llcccc}
\hline \multirow{2}{*}{$\mathrm{DAA}^{\mathrm{z}}$} & & \multicolumn{4}{c}{${ }^{13} \mathrm{C}$ in fruit $(\mathrm{mg})$} \\
\cline { 3 - 6 } & Cultivar & Flesh & Core & Pedicel & Total \\
\hline \multirow{3}{*}{60} & Shinkou & 0.37 & 0.11 & 0.06 & 0.54 \\
& Atago & 0.78 & 0.09 & 0.05 & 0.92 \\
& & $\mathrm{NS}$ & $\mathrm{NS}$ & $\mathrm{NS}$ & $\mathrm{NS}$ \\
& Shinkou & 0.00 & 0.14 & 0.08 & 0.22 \\
110 & Atago & 1.29 & 0.24 & 0.10 & 1.63 \\
& & $* *$ & $\mathrm{NS}$ & $\mathrm{NS}$ & $* *$ \\
& Shinkou & 3.09 & 0.50 & 0.12 & 3.71 \\
150 & Atago & 2.90 & 0.71 & 0.08 & 3.69 \\
& & NS & NS & NS & NS \\
& Shinkou & 0.00 & 0.40 & 0.07 & 0.47 \\
190 & Atago & 10.68 & 0.00 & 0.03 & 10.71 \\
& & $* *$ & NS & NS & $* *$ \\
& Shinkou & 0.00 & 0.00 & 0.04 & 0.04 \\
& Atago & 26.03 & 0.31 & 0.12 & 26.46 \\
& & $* *$ & NS & $*$ & $* *$ \\
\hline
\end{tabular}

2DAA = days after anthesis.

${ }^{13} \mathrm{CO}_{2}$ labeling date.

Ns, *,**Nonsignificant or significant at $P<0.05$ or 0.01 , respectively, by $t$ test.

not separated for calculation. The patterns of ${ }^{13} \mathrm{C}$ losses varied with cultivars and stages of fruit development (Table 3). At the initial stage of fruit development characterized with active cell division (30 and 60 DAA), a higher proportion of ${ }^{13} \mathrm{C}$ was used for respiration and export of the spur in 'Shinkou' than that in 'Atago'. At the stage of rapid fruit growth (110 DAA), few losses of ${ }^{13} \mathrm{C}$ were measured in both cultivars. However, the ${ }^{13} \mathrm{C}$ losses of respiration and export increased again in 'Shinkou' and 'Atago' at 150 and 190 DAA, respectively.
SINK STRENGTH AND RELATIVE SINK STRENGTH. The results of calculation of RSS showed that although the RSS of individual organs varies with the time of season, the RSS of fruit was dominant over those of other organs in the spur in both cultivars on each labeling date except at 30 DAA (Fig. 3). Regardless of the period of ${ }^{13} \mathrm{C}$ labeling, the percentage of RSS of the flesh in 'Atago' was higher than that of 'Shinkou'. On the contrary, 'Shinkou' with a lager core had a higher RSS than 'Atago' with a smaller core. At 30 DAA, leaves were still primary sinks and lots of ${ }^{13} \mathrm{C}$ were invested in leaf growth, and thereafter the percentage of RSS of the leaf remained a relatively lower level. It was intriguing that a little increase in the percentage of RSS of the leaf in 'Shinkou' was observed at 150 DAA. Although current shoot, old wood, and pedicel accounted for a small portion of the total RSS of the spur unit, their RSS varied with the stages of fruit development in both cultivars. The RSS of current shoot and old wood in 'Shinkou' at 60 and 150 DAA were significantly higher than those in 'Atago', respectively.

\section{Discussion}

Fruiting spur was the primary structure in both cultivars as shown in Table 2. As with apple, spur characteristics also play an important role during fruit development in japanese pears (Ferree et al., 2001; Zhang, 2003). Spur-leaf-derived photosynthates were the main source in japanese pears, so leaf characteristics and growth were crucial factors for fruit development, especially during the initial stage of fruit development (Hayashi and Tanabe, 1991; Teng et al., 2002; Zhang, 2003). SLW, total leaf area per spur, leaf emergence rate, fruit number per spur, and pedicel development were suggested to be related to fruit development in japanese pears (Zhang, 2003). Although total leaf area per spur in 'Shinkou' was greater than that in 'Atago' before 8 WAA, few differences were observed in the amount of ${ }^{13} \mathrm{C}$ assimilates 
Table 5. Amount of ${ }^{13} \mathrm{C}$ allocated to individual organs of fruiting spur $7 \mathrm{~d}$ after ${ }^{13} \mathrm{CO}_{2}$ labeling in two late-maturing japanese pear cultivars, 'Shinkou' and 'Atago' $(n=4)$.

\begin{tabular}{|c|c|c|c|c|c|c|c|c|}
\hline \multirow[b]{2}{*}{ DAA $^{z}$} & \multirow[b]{2}{*}{ Cultivar } & \multirow{2}{*}{$\begin{array}{l}\text { Leaf } \\
\text { (mg) }\end{array}$} & \multirow{2}{*}{$\begin{array}{c}\text { Current } \\
\text { shoot } \\
\text { (mg) }\end{array}$} & \multirow{2}{*}{$\begin{array}{c}\text { Old } \\
\text { wood } \\
(\mathrm{mg})\end{array}$} & \multicolumn{4}{|c|}{ Fruit (mg) } \\
\hline & & & & & Flesh & Core & Pedicel & Total \\
\hline \multirow[t]{3}{*}{$30 y$} & Shinkou & 6.41 & 1.00 & 0.19 & 4.09 & 1.31 & 0.20 & 5.60 \\
\hline & Atago & 8.54 & 0.97 & 0.90 & 8.06 & 1.28 & 0.33 & 9.67 \\
\hline & & NS & NS & NS & $* *$ & NS & $* *$ & $* *$ \\
\hline \multirow[t]{3}{*}{60} & Shinkou & 2.12 & 0.79 & 0.44 & 4.18 & 2.09 & 0.16 & 6.43 \\
\hline & Atago & 3.49 & 0.50 & 0.27 & 13.46 & 2.95 & 0.20 & 16.61 \\
\hline & & NS & NS & NS & $* *$ & NS & NS & $* *$ \\
\hline \multirow[t]{3}{*}{110} & Shinkou & 2.61 & 0.37 & 0.30 & 19.73 & 3.68 & 0.11 & 23.52 \\
\hline & Atago & 3.09 & 0.88 & 0.36 & 24.07 & 1.72 & 0.09 & 25.88 \\
\hline & & NS & NS & NS & NS & NS & NS & NS \\
\hline \multirow[t]{3}{*}{150} & Shinkou & 3.64 & 0.37 & 0.35 & 8.37 & 0.84 & 0.09 & 9.30 \\
\hline & Atago & 1.42 & 0.51 & 0.09 & 28.83 & 0.25 & 0.03 & 29.11 \\
\hline & & NS & NS & NS & $* *$ & NS & $*$ & $* *$ \\
\hline \multirow[t]{3}{*}{190} & Shinkou & 4.61 & 0.36 & 0.14 & 15.34 & 4.87 & 0.07 & 20.28 \\
\hline & Atago & 3.17 & 0.33 & 0.25 & 29.82 & 0.31 & 0.14 & 30.27 \\
\hline & & NS & NS & NS & $*$ & $*$ & NS & $*$ \\
\hline
\end{tabular}

${ }^{2 \mathrm{DAA}}=$ days after anthesis.

${ }^{113} \mathrm{CO}_{2}$ labeling date.

NS, ***Nonsignificant or significant at $P<0.05$ or 0.01 , respectively, by $t$ test.

produced by spur leaves between the two cultivars. It is of interest that a higher proportion and amount of ${ }^{13} \mathrm{C}$ allocated to fruit of 'Atago' were measured. These results indicate that RSS of 'Atago' fruit is greater than that of 'Shinkou'. However, the result of RSS analysis also strongly supports the above suggestion (Fig. 3). Furthermore, leaf characteristics, such as SLW and leaf thickness, are usually regarded as indicators for leaf photosynthesis abilities in apple (Tustin et al, 1992). No significant differences were found in the above leaf parameters between cultivars, and these results also agreed with net photosynthesis (Pn) of leaf and amount of ${ }^{13} \mathrm{C}$ assimilates produced by spur leaves $2 \mathrm{~h}$ after labeling (Tables 1 and 3).

Like other deciduous fruit trees, the early growth of pear fruit depends on both stored carbohydrates and currently produced photosynthates, and thereafter fruit growth depends totally on current photosynthates (Hansen, 1971; Hayashi and Tanabe, 1991; Teng et al., 1999). Early bourse shoot development has been shown to compete with fruitlet growth for photosynthates and also retain and utilize their own assimilates in apple (Jackson, 2003; Tustin et al., 1992). Subsequently, the leaves of bourse shoot become exporters to the fruitlets. The fruit become dominant importers of assimilates from bourse shoot, extension shoot, and nonfruiting as well as fruiting spur leaves. However, competition for photosynthates between bourse shoots and fruit in the same spur was not recognized in 'Nijisseiki' pear during the early developmental stage of fruit (Teng et al., 2002). On the contrary, photosynthates derived from different shoot types may affect fruit development differently. The studies in japanese pear have partially elucidated translocation patterns of photosynthates from different shoot types (Teng et al., 2002). Bourse leaves contributed to fruit from 1.1\% to more than $21 \%$ of photosynthates, and both spur and bourse leaves exported photosynthates out of the spur complex in ' $\mathrm{Ni}$ jisseiki' pear by 13 WAA. It has been shown that water shoots never supply assimilates to fruit even if they are nearby in apple (Jackson, 2003), However, the translocation patterns of photosynthates in vegetative shoots and water shoots remain unknown in japanese pear. The investigation of shoot types showed that 'Shinkou' and 'Atago' were all spur-type cultivars, but 'Atago' had a higher proportion of vegetative shoots with $15.56 \%$ than that in 'Shinkou' with $4.75 \%$. In apple, rapidly growing shoot tips are a strong sink for assimilates, and after the first five or six shoot leaves have been produced photosynthesis the shoot become a more important carbon source than reserves (Hansen, 1971). Photosynthates from the upper leaves of the shoot are generally exported upwards, those from the lower part being exported to other parts of the tree (Jackson, 2003). As a consequence, it is believed that the photosynthates allocated to fruit in 'Shinkou' were primarily obtained from proximate leaves of fruiting spur while more photosynthates from vegetative shoots and bourse shoots would feed the developing fruit in 'Atago'. In general, bourse shoots and vegetative shoots were temporarily terminated in late July. However, a second growth stage of bourse shoots and vegetative shoots of 'Shinkou' was observed in July (Table 2). Certainly, it would be expected that fruit enlargement of japanese pear was affected by the competition of available photoassimilates between shoots and fruit (Furuta, 2000). However, detailed studies are needed to clarify the competition between them further.

Respiratory and export losses of currently assimilated carbon during $7 \mathrm{~d}$ after ${ }^{13} \mathrm{C}$ labeling were normalized by expressing them as a percentage of net C-photosynthesis, thus enabling comparisons to be made between cultivars at different stages. At 30 and 60 DAA, a considerable proportion of losses of currently assimilated carbon occurred in both cultivars, especially higher in 'Shinkou'. In apple and japanese pear, the fruit usually displayed a high respiration rate early in development with active cell division and subsequently declined as fruit matured (Bepete and Lasko, 1997; Downs et al., 1991). The period of cell division in late-maturing japanese pears generally lasts for $\approx 50-60$ DAA (Hayashi and Tanabe, 1991; Toyama and Hayashi, 1956). Leaf dark respiration is the greatest at full bloom and immediately afterwards, and then declines. Also, stem respiration peaks at about the time the leaves emerge from the buds, presumably at the time of maximum mobilization of reserves (Lasko et al., 1999). In the current study, we did not divide the total losses from the spur unit into respiration and export or losses of individual organ, but it is reasonable to assume that apart from the losses for leaf respiration, 

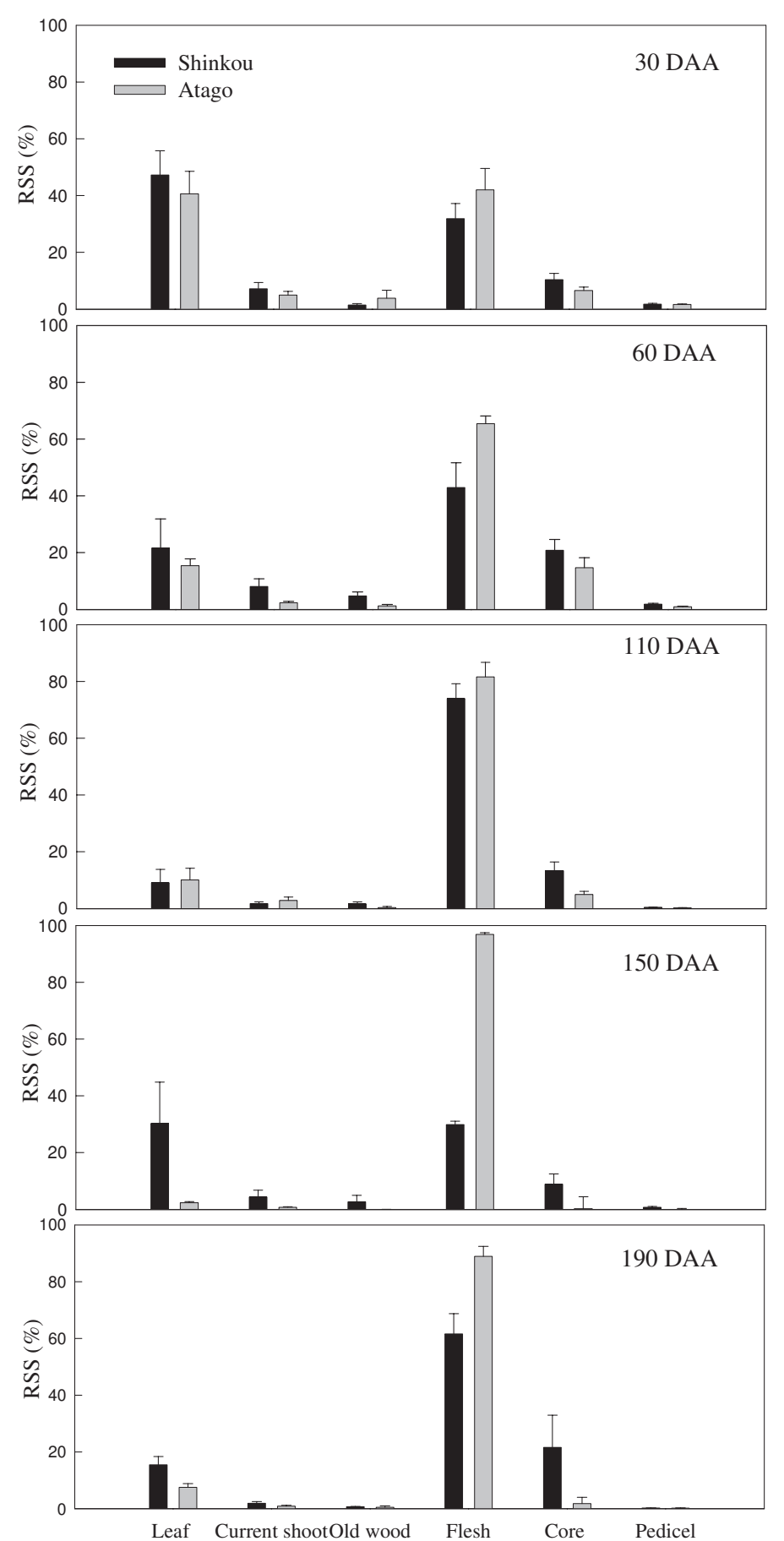

Fig. 3. Relative sink strength (RSS) of individual organs in fruiting spurs during fruit growth in two late-maturing japanese pear cultivars, 'Shinkou' and 'Atago' The vertical bars represent means $\pm \operatorname{SE}(n=4)$.

considerable losses were utilized for fruit respiration because of active cell division in fruit during early fruit development. However, a portion of the total losses was due to the export from the spur at this stage since the presence of obvious ${ }^{13} \mathrm{C}$ abundance in old wood (Table 6). In 'Nijisseiki' pear, there is a transition period of carbohydrates in lateral branches with the decline of reserves and the continous increase of photoassimilates at 4 WAA (Hayashi and Tanabe, 1991). The higher proportion of losses for respiration and export in 'Shinkou' was probably brought about by the larger core structure with higher RSS and few vegetative shoots for low carbohydrate availability to reserve in the stems
(Tables 1-3). By comparison with 'Atago', a higher abundance of ${ }^{13} \mathrm{C}$ and RSS of old wood in 'Shinkou' at 67 DAA also evidently reinforced the above explanation (Tables 3 and 6).

During the stage of rapid fruit growth, few losses of respiration and export were measured and no differences were detected between the two cultivars. However, an earlier dramatic increase in losses of ${ }^{13} \mathrm{C}$ in 'Shinkou' was recorded at $150 \mathrm{DAA}$ than that in 'Atago' at 190 DAA (Table 3). It could be interpreted that the earlier fruit maturation in 'Shinkou' resulted in an earlier shift of photoassimilates from accumulation in fruit to storage in stems compared to 'Atago'. However, since the cessation of fruit enlargement and the onset of fruit maturation in 'Shinkou' around 150 DAA (Fig. 1), the fruit shifts from an active sink with accumulation of carbohydrates to a relative weak sink with the primary events of ripening-related changes in fruit texture. The different patterns of ${ }^{13} \mathrm{C}$ abundance in pedicels and old wood from 117 to 197 DAA also strongly supported the above suggestion (Table 6). Furthermore, in contrast to 'Atago', a dramatic accumulation of ${ }^{13} \mathrm{C}$ and significantly higher ${ }^{13} \mathrm{C}$ abundance in the core were observed again at 197 DAA in 'Shinkou' (Tables 5 and 6). In addition, the differences in duration of fruit enlargement (Fig. 2) should be another factor for clear differences in fruit weight and fruit size between the two cultivars, although they have similar periods of fruit growth.

The observation of ${ }^{13} \mathrm{C}$ allocation in the spur unit of japanese pear showed that in $2 \mathrm{~h}$ after ${ }^{13} \mathrm{C}$ labeling the majority of ${ }^{13} \mathrm{C}$ remained in leaves and fruit during early fruit development, the amount of ${ }^{13} \mathrm{C}$ in leaf remained relatively steady, and almost no ${ }^{13} \mathrm{C}$ photoassimilates were exported $7 \mathrm{~d}$ after ${ }^{13} \mathrm{C}$ labeling (Teng et al., 2001) Therefore, the spurs were harvested $2 \mathrm{~h}$ and $7 \mathrm{~d}$ after ${ }^{13} \mathrm{CO}_{2}$ exposure for analysis of carbon partitioning in this study. The results of trace experiment showed that there were no differences in the amount of photosynthates produced by spur leaves on a spur basis between cultivars on each labeling date except at 190 DAA; however, photosynthates allocated to fruit significantly different between the two cultivars at $37,67,157$, and 197 DAA except at 117 DAA.

In general, a source can be crudely defined as an organ that is a net exporter of carbon assimilates. Source strength refers to the rate at which carbon assimilates are produced and it is involved in the partitioning of photosynthates in the plant (Marcelis, 1996). In the current study, the leaf is considered as the only source in the spur unit and the amount of ${ }^{13} \mathrm{C}$ photoassimilates produced by spur leaves during $2 \mathrm{~h}$ after labeling was regarded as an indicator of source strength. The results of the amount of ${ }^{13} \mathrm{C}$ recovered in spurs indicate that there were no significant differences in source strength between cultivars with the exception of that at 190 DAA (Table 3).

However, it is well known that the photoassimilates allocated to flesh were critical for flesh growth because the number and size of cortical cells were primary responsible for the final fruit size (Toyama and Hayashi, 1956). The results revealed that there were more photoassimilates invested in flesh growth in 'Atago' than that in 'Shinkou' on each measuring date except at 117 DAA (Table 5). Generally, sink strength defines the ability of each sink to accumulate assimilates from source leaves, but the variations of ability are due to differences in sink size and sink activity in different cultivars, as well as their distance from and relative position to the source leaves (Shishido et al., 1999). To elucidate the relationship of sink strength between cultivars in this study, a normalized RSS value is a suitable index because it is a ratio comparing the sink activity of each sink with the average 
Table 6. The abundance (atom\%) of ${ }^{13} \mathrm{C}$ incorporated into individual organs of fruiting spur $7 \mathrm{~d}$ after ${ }^{13} \mathrm{CO}_{2}$ labeling in two late-maturing japanese pear cultivars, 'Shinkou' and 'Atago' $(n=4)$.

\begin{tabular}{llcccccc}
\hline & & & Current & Old & \multicolumn{3}{c}{ Fruit } \\
\cline { 6 - 8 } DAA $^{z}$ & Cultivar & Leaf & shoot & wood & Flesh & Core & Pedicel \\
\hline $30 y$ & Shinkou & $0.253^{\mathrm{x}}$ & 0.334 & 0.099 & 0.604 & 0.534 & 0.477 \\
& Atago & 0.520 & 0.596 & 0.140 & 1.144 & 0.942 & 0.816 \\
& & $* *$ & $* *$ & NS & $* *$ & $* *$ & $* *$ \\
60 & Shinkou & 0.076 & 0.186 & 0.123 & 0.292 & 0.271 & 0.233 \\
& Atago & 0.135 & 0.146 & 0.072 & 0.410 & 0.403 & 0.248 \\
& & NS & NS & $* *$ & $*$ & $*$ & NS \\
110 & Shinkou & 0.110 & 0.109 & 0.094 & 0.290 & 0.259 & 0.130 \\
& Atago & 0.115 & 0.156 & 0.064 & 0.131 & 0.084 & 0.075 \\
& & NS & NS & NS & $*$ & $*$ & $* *$ \\
& Shinkou & 0.170 & 0.093 & 0.083 & 0.029 & 0.036 & 0.075 \\
& Atago & 0.052 & 0.079 & 0.018 & 0.061 & 0.024 & 0.021 \\
& & $*$ & NS & $*$ & NS & NS & $*$ \\
& Shinkou & 0.157 & 0.075 & 0.035 & 0.048 & 0.131 & 0.046 \\
& Atago & 0.111 & 0.071 & 0.048 & 0.061 & 0.038 & 0.085 \\
& & NS & NS & NS & NS & $*$ & $*$ \\
\hline DAA & & & & & & & $*$
\end{tabular}

${ }^{2} \mathrm{DAA}=$ days after anthesis.

${ }^{\mathrm{y} 13} \mathrm{CO}_{2}$ labeling date.

${ }^{x}$ The natural ${ }^{13} \mathrm{C}$ abundance of individual organs has been excluded.

NS, ***Nonsignificant or significant at $P<0.05$ or 0.01 , respectively, by $t$ test.
It is generally agreed that the availability of carbohydrates to an individual organ is dependent upon the supply of resources from source organs and the demand for resources by sink organs. Sink demand is the sum of the carbohydrate requirements for maintenance and growth of the sink organ. Under the nonlimiting resource conditions, organ growth is limited only by endogenous characteristics of the organ (Wareing and Patrick, 1975). As mentioned above, therefore, it seems that the movement of photosynthates into the fruit was determined by sink strength of the fruit rather than the source strength in the two cultivars. Thus, factors that increase sink strength of fruit, such as plant growth regulators, or factors that increase the supply of resource availability, such as low cropload, may be expected to increase fruit size in japanese pear.

\section{Literature Cited}

size and sink activity of the whole spur, and it is defined as the relative strength of all sinks to source leaves, which adjusted the effects of sink size and sink activity. The results of the RSS of individual organs were compatible with the patterns of amount of ${ }^{13} \mathrm{C}$ recovered at 7 DAL in both cultivars (Table 3, Fig. 3). A little increment of RSS of the leaf in 'Shinkou' at 157 DAA may be partially due to the decline of the rate of carbon export and the accumulation of ${ }^{13} \mathrm{C}$ in leaves.

Many investigators have reported that heavy croploads result in smaller fruit than light cropping because of source limitation, and accordingly, fruit thinning is widely used to increase the final size of the remaining fruit on the trees (Genard et al., 1998; Grossman and DeJong, 1995a, 1995b; Hayashi and Tanabe, 1991; Jackson, 2003; Lasko, 1994). To produce larger fruit, the normal cropload levels of japanese pear are usually adjusted to around $10 \mathrm{fruit} / \mathrm{m}^{2}$ on the early- and medium-maturing cultivars and 5-6 fruit $/ \mathrm{m}^{2}$ on the late-maturing cultivars in Japan (Mitobei, 2000). In the present study, the cropload level is expressed with fruit $/ \mathrm{cm}^{2}$ of TCA instead of fruit $/ \mathrm{m}^{2}$; the range of croploads for the two cultivars is $0.8-1.5$ fruit $/ \mathrm{cm}^{2}$ of TCA. It seems that the low croploads on both cultivars in this type of management system should result in the nonlimiting resource availability. Additionally, fruit size could not be retrieved by reducing cropload in 'Shinkou' (Machida, 2000), which also implies that there is no source limitation in this type of management practice. It has been shown that maximum organ growth potential is genetically determined and is attained when an organ is grown under optimal environmental conditions in the presence of a nonlimiting supply of carbon and other resources (DeJong, 1999; Farrar, 1993; Grossman and DeJong, 1995a, 1995b). As a consequence, the fruit could be expected to grow near their genetically determined growth rate and the carbon partitioning patterns found in the spurs are probably largely reflecting the differences in RSS throughout the season. In other words, the genetic differences should be the primary factors that determine the differences in fruit growth and development between the two cultivars and these differences create the differences in carbon partitioning to the fruit when croploads are low. relationships to fruit growth rate, temperature, and light exposure. Acta Hort. 451:319-326.

DeJong, T.M. 1999. Developmental and environmental control of drymatter partitioning in peach. Hortscience 34:1037-1040.

Downs, C.G., C.J. Brady, J. Campbell, and W.B. McGlasson. 1991. Normal ripening cultivars of Pyrus serotina are either climacteric or non-climacteric. Scientia Hort. 48:213-221.

Farrar, J.F. 1993. Sink strength: What is it and how do we measure it? Plant. Cell. Environ. 16:1045-1046.

Ferree, D.C., B.L. Bishop, J.R. Schupp, D.S. Tustin, and W.M. Cashmore. 2001. Influence of flower type, position in the cluster and spur characteristics on fruit set and growth of apple cultivars. J. Hort. Sci. Biotechnol. 76:1-8.

Furuta, O. 2000. Shoot growth and fruit enlargement in japanese pear, p. 189-194. In: Pear (in Japanese). Encyclopaedia of fruit tree. Rural Culture Assn. Press, Tokyo, Japan.

Garriz, P.I., G.M. Colavita, and H.L. Alvarez. 1998. Fruit and spur leaf growth and quality as influenced by low irradiance levels in pear. Scientia Hort. 77:195-205.

Genard, M., F. Lescourret, M.B. Mimoun, J. Besset, and C. Bussi. 1998. A simulation of growth at the shoot-bearing fruit level. II. Test and effect of source and sink factors in the case of peach. Eur. J. Agron. 9:189-202.

Grossman, Y.L. and T.M. DeJong. 1995a. Maximum fruit growth potential and seasonal patterns of resource limitation during peach growth. Ann. Bot. 75:553-560.

Grossman, Y.L. and T.M. DeJong. 1995b. Maximum fruit growth potential following resource limitation during peach growth. Ann. Bot. 75:561-567.

Hansen, P. $1971 .{ }^{14} \mathrm{C}$ studies on apple trees. VII. The early seasonal growth in leaves, flowers and shoots as dependent upon current photosynthates and existing reserves. Physiol. Plant. 25:469-473.

Hayashi. S and K. Tanabe. 1991. Basic knowledge for fruit tree culture (in Japanese). Agr. Assn. Press, Tottori, Japan.

Ho, L.C. 1988. Metabolism and compartmentation of imported sugars in sink organs in relation to sink strength. Annu. Rev. Plant Physiol. Plant Mol. Biol. 39:355-378.
Bepete, M. and A.N. Lasko. 1997. Apple fruit respiration in the field: 
Jackson, J.E. 2003. Biology of apples and pears. Cambridge Univ. Press, Cambridge, U.K.

Kouchi, H. and T. Yoneyama. 1984. Dynamics of carbon photosynthetically assimilated in nodulated soybean plants under steady-state conditions. I. Development and application of ${ }^{13} \mathrm{CO}_{2}$ assimilation system at a constant ${ }^{13} \mathrm{C}$ abundance. Ann. Bot. 53:875-882.

Laney, R.E.C. and H.A. Quamme. 1975. Pears, p. 38-70. In: J. Janick and J.N. Moore (eds.). Advances in fruit breeding. Purdue Univ. Press, West Lafayette, Ind.

Lakso, A.N. 1994. Apple, p. 3-42. In: B. Schaffer and P.C. Anderson (eds.). Handbook of environmental physiology of fruit crops, vol. I. Temperate crops. CRC Press, Boca Raton, Fla.

Lakso, A.N., J.N. Wünsche, J.W. Palmer, and L.Corelli Grappadelli. 1999. Measurement and modeling of carbon balance of the apple tree. Hortscience 34:1040-1047.

Machida, Y. 2000. The cultivar differences of production in japanese pears, p. 73-78. In: Pear (in Japanese). Encyclopaedia of fruit tree. Rural Culture Assn. Press, Tokyol.

Marcelis, L.F.M. 1996. Sink strength as determinant of dry matter partitioning in the whole plant. J. Expt. Bot. 47:1281-1291.

Mitobei, M. 2000. The relationship between fruit size and cropload in japanese pear, p. 143-146. In: Pear (in Japanese). Encyclopaedia of fruit tree. Rural Culture Assn. Press, Tokyo.

National Institute of Fruit Tree Science, Japan. 2002. The statistical data of pear production in Japan in 2001. 21 July 2004. <http://www.fruit. affrc.go.jp/kajunoheya/ikuseihinsyu/data/nasi.html>

Okano, K., O. Ito, N. Kokubun, and T. Totsuka. 1983. Determination of ${ }^{13} \mathrm{C}$ in plant materials by infrared absorption spectrometry using a simple calibration method. Soil. Sci. Plant. Nutr. 29:369-374.

Raskin, I. 1983. A method for measuring leaf volume, density, thickness, and internal gas volume. HortScience 18:698-699.

Rom, C.R. and D.C. Ferree. 1984. Spur leaf characteristics of nine apple cultivars. Fruit Var. J. 38:2-5.

Shishido, Y., H. Kumakura, and T. Nishizawa. 1999. Carbon balance of a whole tomato plant and the contribution of source leaves to sink growth using ${ }^{14} \mathrm{CO}_{2}$ steady-state feeding method. Physiol. Plant. 106:402-408.

Teng, Y., K.Tanabe, F. Tamura, and A. Itai. 1998. Effects of spur age on the translation of assimilates from spurs of 'Nijisseiki' pear (Pyrus pyrifolia Nakai). J. Jpn. Soc. Hort. Sci. 67:313-318.

Teng, Y., K.Tanabe, F. Tamura, and A. Itai. 1999. Partitioning pattern of ${ }^{13} \mathrm{C}$-assimilates in 'Nijisseiki' pear tress during the initial period of fruit growth. J. Jpn. Soc. Hort. Sci. 68:1079-1083.

Teng, Y., K.Tanabe, F. Tamura, and A. Itai. 2001. Fate of photosynthates from spur leaves of 'Nijisseiki' pear during the period of rapid fruit growth. J. Hort. Sci. Biotechnol. 76:300-304.

Teng, Y., K.Tanabe, F. Tamura, and T. Nakai. 2002. Partitioning pattern of photosynthates from different shoot types in 'Nijisseiki' pear (Pyrus pyrifolia Nakai). J. Hort. Sci. Biotechnol. 77:758-765.

Toyama, S. and S. Hayashi. 1956. Studies on the fruit development of japanese pears (in Japanese). J. Jpn. Soc. Hort. Sci. 25:274 -282.

Treder, J. and M. Kubik. 2000. Growth, flowering and partitioning of ${ }^{14} \mathrm{C}$-assimilate in oriental lily 'Star Gazer' as affected by light level and flower removal. J. Hort. Sci. Biotechnol. 75:277-282.

Tustin, S., B. Corelli-Grappadelli, and G. Ravaglia. 1992. Effect of previous-season and current light environments on early-season spur development and assimilate translocation in 'golden Delicious' apple. J. Hort. Sci. 67:351-360.

Wareing, P.F. and J. Patrick. 1975. Source-sink relations and the partition of assimilates in the plant, p. 481-499. In: J.P. Cooper (ed.). Photosynthesis and productivity in different environments. Cambridge Univ. Press, Cambridge, U.K.

Yamamoto, T. 2001. Translocation of ${ }^{13} \mathrm{C}$-photosynthates among 2-yearold branches during the rapid fruit growth stage of cherry, pear, apple and persimmon fruit. J. Jpn. Soc. Hort. Sci. 70:170-177.

Zhang,C.X. 2003. The cultivar difference in partitioning of photosynthates from spur leaves during fruit development in japanese pear (Pyrus pyrifolia Nakai). MS thesis, Univ. Tottori, Tottori, Japan. 